\title{
SUPPOSED OVOVIVIPARITY AND VIVIPARITY IN THE COCONUT MITE, ACERIA GUERRERONIS KEIFER (PROSTIGMATA: ERIOPHYIDAE), AS A RESULT OF FEMALE SENILITY
}

\author{
Denise Navia, ${ }^{1}$ Carlos H. W. Flechtmann ${ }^{2}$ and James W. Amrine, $\mathbf{J r}^{3}$ \\ 1. Embrapa Recursos Genéticos e Biotecnologia, Cx. Postal 02372, 70.770-900 Brasilia, DF, Brazil, e-mail: \\ navia@cenargen.embrapa.br; 2. CNPq-Brazil Researcher, Departamento de Entomologia, Fitopatologia e Zoologia \\ Agrícola, ESALQ/Universidade de São Paulo, Cx. Postal 9, 13.418-900 Piracicaba, SP, Brazil, e-mail: \\ chwflech@esalq.usp.br; 3. Division of Plant and Soil Sciences, West Virginia University, Morgantown,WV \\ 26506-6108, USA.
}

\begin{abstract}
Senescent females showing apparent ovoviviparity and/or viviparity in Aceria guerreronis Keifer are reported from Brazil, India and Sri Lanka populations; the phenomenon is explained. Keywords - Acari, Eriophyidae, reproduction, embryonic development, Brazil, India, Sri Lanka.
\end{abstract}

\section{INTRODUCTION}

Eriophyoid mites are entirely oviparous. However, apparent ovoviviparity, in the sense of eggs being laid containing embryos in an advanced state of development with eclosion occurring soon after they are laid, or viviparity, when a female produces living young instead of eggs (Evans, 1992), has been reported. These reports are instances of misunderstanding of female senility; females just became too old and feeble to lay eggs. Some reports consider the species facultatively ovoviviparous or exclusively viviparous, based on observations of egg cleavage and embryo development into nymphs which hatch within females. "Ovoviviparity" had been reported in Aceria caulobia (Nalepa) (de Lillo, 1991), Aceria chondriphora Keifer (Briones and McDaniel, 1976), Aceria stefanii (Nalepa) (de Lillo, 1986), Eriophyes laevis (Nalepa) (Shevchenko, 1961), Metaculus mangiferae (Attiah) (Abou-Awad, 1981), Phyllocoptruta oleivora (Ashmead) (Hall, 1967), Phytoptus avellanae Nalepa (Nalepa, 1889; (in de Lillo, 1991), and Vasates quadripedes Shimer (Hall, 1967). "Viviparity" had been reported in Aculus ulae Boczek and Rhyncaphytoptus ulmivagrans Keifer (Boczek, 1961; ChannaBasavanna, 1966). Rhynca- phytoptus ficifoliae Keifer was reported to be an exclusively viviparous form, lacking the egg stage by Abou-Awad et al. (2000). These authors may have failed to observe the eggs which in some species are flattened against the leaf and are transparent. Amrine (1996, unpubl.) collected flattened, sculptured eggs of Aculus ulae on upper surfaces of Carpinus betulus leaves in Morgantown, WV.

The coconut mite Aceria guerreronis Keifer has moved from E. Africa to Sri Lanka and South India (Moore, 2000). It is a severe pest in these new territories causing severe drop of fruits. Several countries have extensive research programs on the coconut mite and we have been making confirmations of submitted specimens.

\section{MATERIAL AND METHODS}

During morphometric studies on the coconut mite Aceria guerreronis Keifer, specimens from 26 populations from nine countries in America, Africa and Asia Benin, Brasil, Cuba, India, Mexico, Sri Lanka, Tanzania, USA and Venezuela - collected from coconut (Cocos nucifera L.) fruits and from San Diego, CA, USA, collected from Syagrus romanzoffiana (Cham.) Glassm. buds were studied. Specimens from Brazil were alive

* This research was completed at Setor de Zoologia Agrícola, ESALQ-USP, Piracicaba, SP, Brasil as a part of a thesis submitted by the senior author in partial fulfillment of the requirements for the Ph.D degree. 

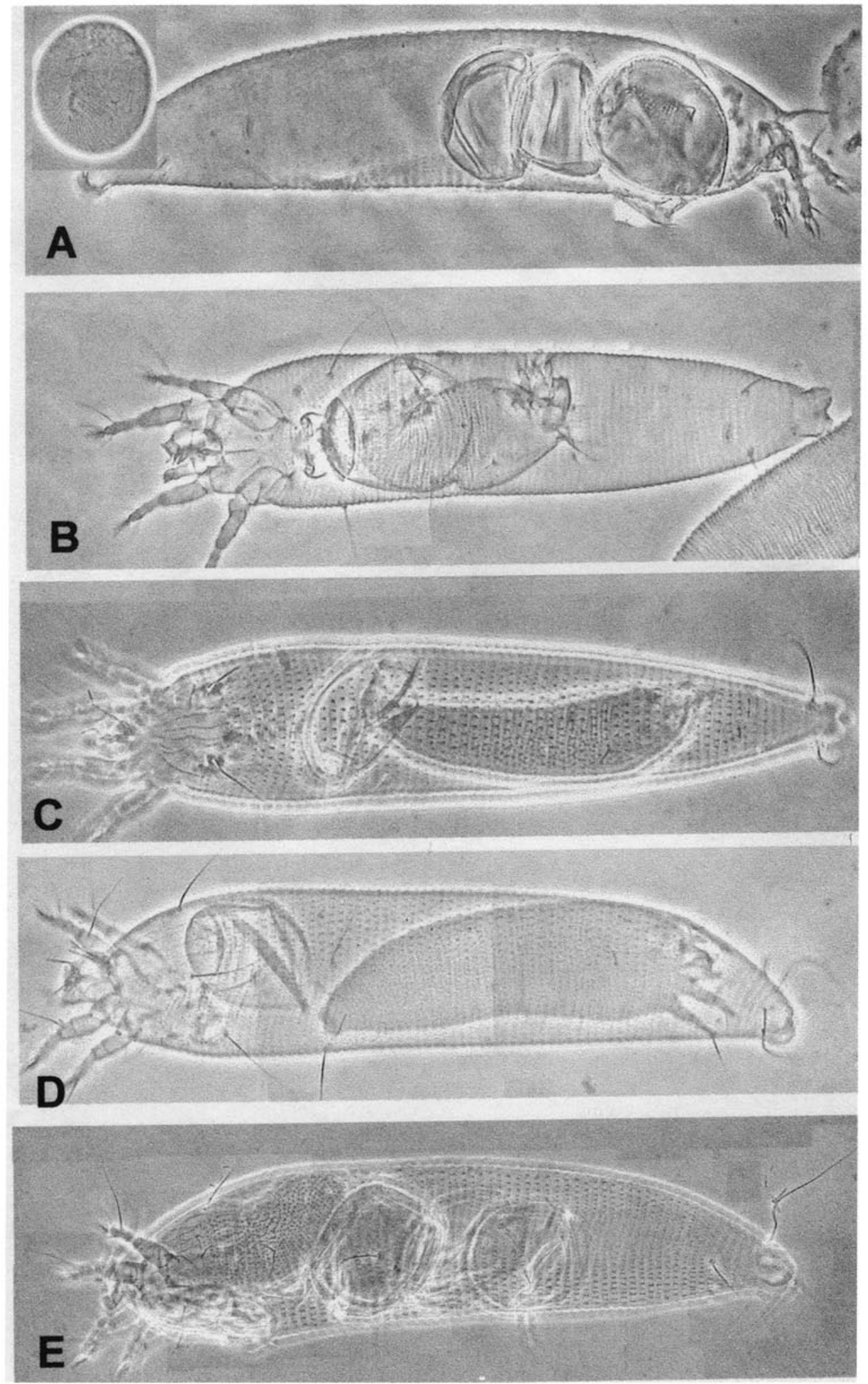

Fig. 1. Phase-contrast micrographs of Aceria guerreronis reproducing females - A. Chorions within a female and an anterior egg containing a formed larva; B, C and D. larva eclosing inside a female directed toward the posterior part of her body and ruptured chorion; E. larva eclosing inside a female directed toward the anterior part of her body with ruptured chorions and/or developing eggs. 
when mounted; specimens from other countries were in $70 \%$ ethyl alcohol. About 50 specimens from each population were mounted in modified Berlese medium and observed with a phase contrast microscope.

\section{RESULTS}

Signs of supposed ovoviviparity were observed in about $5-10 \%$ of specimens from the States of Alagoas and Bahia, Brazil; Kerala, India; and Kalpitiya, Madampe and Madurankuliya, Sri Lanka. Eggs in advanced stage of embryonic development; chorions and larvae were observed inside senescent female bodies (Fig. 1). Some larvae had the gnathosoma directed toward the posterior part of the mother (Figs. 1b, c, d) while others had the gnathosoma directed toward the anterior (Fig. le). It is possible that in the case of individuals containing chorion remnants (Figs. 1a, e), the larvae may have emerged through the mother's genital opening without harming her as reported in A. caulobius by de Lillo (1991).

\section{DISCUSSION}

Jeppson et al. (1975) proposed several hypotheses to explain the occurrence of ovoviviparity or viviparity in mites. However conditions influencing this reproductive strategy is not well known. Filiponni and Francaviglia (1964) have shown that in some species of Macrocheles Latreille the length of time the eggs are retained in the female reproductive tract is influenced by availability of food; plentiful food favored oviparity whereas a shortage of food produced larviparity through the longer retention of the egg in the female genital tract. However, in Spinturnix Heyden (Spinturnicidae), a chiropteran parasite, it occurs in the presence of plentiful food, which is probably essential for the maintenance of high nutritional status in the female during the extended period of embryonic development (Evans, 1992). De Lillo (1991) tried unsuccessfully to establish a relationship between apparent ovoviviparity in A. caulobius, a gall-forming eriophyid mite living on stems of Suaeda fruticosa Forsk., and bioecological factors as density of the gall population, the growth of the galls or the migration of the mites.

Our report here indicates that senescent females may show apparent ovoviviparity and/or apparent viviparity in A. guerreronis. It should be noted, however, that there is no true ovoviviparity or viviparity in eriophyid mites and previous reports of such occurrences in eriophyid mites should be considered erroneous.

\section{ACKNOWLEDGEMENTS}

We are grateful to all researchers who sent us $A$. guerreronis samples, especially to J. E. P. Pitta, M. A. L
Bittencourt, N. S. Aratchige and P. S. P. V. Vidyasagar; to Dr. Gilberto J. de Moraes for valuable suggestions and revision of the manuscript; to T. M. Castro for helping in the photography; to CNPq, Conselho Nacional de Desenvolvimento Científico e Tecnológico, Brazil, for the $\mathrm{Ph}$.D. fellowship and for supporting the page charge.

\section{REFERENCES}

Abou-Awad, B. A. 1981. Bionomics of the mango rust mite, Metaculus mangiferae (Attiah) with description of immature stages. Acarologia 22: 151-155.

Abou-Awad, B. A., B. El-Sawaf, A. S. Reda and A. A. Abdel-Khalek. 2000. Environmental management and biological aspects of two eriophyoid fig mites in Egypt: Aceria ficus and Rhyncaphytoptus ficifoliae. Acarologia 40 (4): 419-429.

Boczek, J. 1961. Studies on eriophyid mites in Poland. Prace Nauk. Inst. Och. Roslin. 3: 5-85.

Briones, M. L. and B. McDaniel. 1976. Eriophyid plant mites of South Dakota. S. Dakota State Univ., Agr. Exp., Tech. Bull. 43: 123 pp.

Channabasavanna, G. P. 1966. A contribution to the knowledge of Indian eriophyid mites (Eriophyoidea: Trombidiformes: Acarina). Univ. Agric. Sci., Hebbal. 153pp.

De Lillo, E. 1986. Ovoviviparità in Aceria stefanii (Nal.) (Acari: Eriophyoidea). Entomologica, Bari 21: 1921.

De Lillo, E. 1991. Preliminary observations of ovoviviparity in the gall-forming mite, Aceria caulobius (Nal.) (Eriophyoidea: Eriophyidae). pp. 223-229. In: Schuster, R. and P. W. Murphy (Eds.). The Acari Reproduction, Development and Life History Strategies. Chapman and Hall, New York.

Evans, G. O. 1992. Principles of Acarology. CAB International, Wallingford, 563pp.

Filipponi, A. and G. Francaviglia. 1964. Larviparita facoltativa in alcuni Macrochelidi (Acari; Mesostigmata) associati a Muscidi di interesse sanitario. Parassitologia 6: 99-113.

Hall, C. C. Jr. 1967. The Eriophyoidea of Kansas. Univ. Kans. Sci. Bull. 47: 601-675.

Jeppson, L. R., H. H. Keifer and E. W. Baker. 1975. Mites Injurious to Economic Plants. Univ. Calif. Press. 614pp.

Moore, D. 2000. Non-chemical control of Aceria guerreronis on coconuts. Biocontrol, News \& Information 21(3): $83 \mathrm{~N}-88 \mathrm{~N}$. CABI, UK. http://pest. cabweb.org/pdf/bni/control/bnira55.pdf

Shevchenko, V. G. 1961. Postembryonic development of the four legged gall mites (Acariformes, Eriophyidae) and observations on the classification of Eriophyes laevis (Nal.). Zool. Zh. 40: 1143-1147. 